\title{
Determination of Saturated and Unsaturated Fatty Acids Amount in Leukocyte Membranes from Subjects Fed with Solid and Fluid Oils
}

\author{
Fazilet Erman', Suleyman Aydin ${ }^{1, *}$, Yasar Demir ${ }^{2}$, Fatih Akcay ${ }^{3}$ and Ebubekir Bakan ${ }^{3}$ \\ ${ }^{1}$ Firat University, School of Medicine, Firat Medical Center, Department of Biochemistry and Clinical Biochemistry, 23119, Elazig, Turkey \\ ${ }^{2}$ Ataturk University, KK Education Faculty, 25240 Erzurum Turkey \\ ${ }^{3}$ Ataturk University, Medicine Faculty, Biochemistry Department, 25240 Erzurum, Turkey
}

Received 13 February 2006, Accepted 21 April 2006

\begin{abstract}
Modifications in dietary fatty acid intake might lead to a modification in membrane phospholipid fatty acid composition. The purpose of this study was to investigate relationship between different type of oil consumption and leukocyte membrane phospholipid composition. This study was carried out in subjects utilizing butter $(n=15)$, margarine $(n=15)$, fluid oil $(n=15)$ and mixed types of oils $(n=15)$ in total 60 subjects. Leukocytes were separated from total blood by dextran sedimentation method. Membrane lipids and proteins were isolated following the cell disruption. Fatty acids of membrane phospholipids were isolated by hydrolysation with phospholipase B under ultrasonic dismembranator. Free fatty acids were identified with gas chromatography at chloroform phase. The results obtained were compared with data obtained by chromatograms of the standards. Results more prominent values of arachidic, dihomo- $\gamma$ linolenic and palmitoleic acids were found in butter-or mixed oil-user groups; eicosadienoic, eicosamonoenoic, dihomo- $\gamma$-linolenic and behenic acids in fluid oil; heptanoic, valeric, eicosadienoic and linolenic acids in margarine groups. The fatty acid composition of mixed oil was similar to butter, while other two oils were so different. From this study, it was concluded that the type of oil consumption might have an influence on phospholipid components of plasma membranes.
\end{abstract}

Keywords: Fatty acid, Membrane, Oil

*To whom correspondence should be addressed.

Tel: 90-533-493-4643; Fax: 90-424-2388660

E-mail: saydin1@hotmail.com

\section{Introduction}

Membranes are essential components of all cells. They form closed components around cellular protoplasm to separate one cell from another, thus permit cellular individuality. Membranes are constructed of a bilayer of amphipathic lipids made up of phospholipids and glycolipids. The relative amount of these two lipids varies with the type of membrane, even between the organelles membranes of the same cell (Finean et al., 1978).

Biological membranes are composed of a lipid bilayer that contains a central core of fatty acyl chains. This hydrophobic core acts as a barrier, preventing the unregulated movement of ions and metabolic products across the membrane. The fatty acyl chains also interact with the proteins that penetrate into the membrane, including enzymes, receptors, and transporters. Most of them have an even number of carbon atoms, between 16 and 22 . About 35 to $45 \%$ are saturated: the remainder is unsaturated and contain between 1 and 6 double bonds (Spector et al., 1987).

The human body has a special protective system against toxic and infectious agents. This system consists of leukocytes, macrophages and lymphoid tissues. Neutrophils and monocytes are the leukocytes that destroy foreign agents by phagocytosis. While neutrophils function by reaching the area of infection via the bloodstream, monocytes function by passing tissues and forming the stationary and mobile macrophage systems, respectively (Barret et al., 1984; Keles et al., 2000).

Leukocytes play an important role in the development and progression of a number of inflammatory and autoimmune disorders, including rheumatoid arthritis, multiple sclerosis, systemic lupus erythematosus and psoriasis, all of which are characterized by the presence of activated T-cells and cytokines at the site of tissue injury and in the circulation.

The $n-3$ polyunsaturated fatty acids (PUFAs), eicosapentaenoic acid (20:5n-3) and docosahexaenoic acid (22:6n-3) are known to modulate immune response, particularly by affecting T-cell function (Zurier et al., 1999; Calder et al., 2001). They are 
also known to stimulate the neutrophil respiratory burst, a response that is amplified in the presence of proinflammatory cytokines (Endres et al., 1993). Accordingly, dietary supplementation with n-3 FAs decreases the production of Tcell-derived cytokines and lymphoproliferation (Endres et al., 1993; Belluzzi et al., 1996). Although fish oil-derived FAs have found clinical applications for the treatment of various inflammatory diseases (Endres et al., 1993; Yaqoob et al., 1995; Zurier et al., 1999) and as adjuvant immunosuppressive agents (Belluzzi et al., 1996), the underlying molecular and cellular mechanisms of PUFA-induced T-cell inhibition have not yet been elucidated in detail. Epidemiological studies have also associated the incidence of mammary tumors in humans with the level of fat in the diet (Tinsley et al., 1981). Many reports of the effects of FAs on cell growth have shown growth stimulation in normal and neoplastic cells (Wicha et al., 1979).

It is well known that dietary fat can influence the fatty acid (FA) composition of tissue lipids, including those of cell membranes. This may alter various properties of the membranes such as integrity, fluidity, permeability and distribution of receptor sites (Hopkins et al., 1976). In the present report, we have focused our attention on the lipid composition of membranes of leukocytes, which are the important component of the defense system of the body, and to investigate the effect of dietary fat intake on the membrane composition of leukocytes.

\section{Materials and Methods}

Subjects and blood sample collection. The participants were categorized as butter (bearing $2.5 \mathrm{mg} / \mathrm{g}$ cholesterol) $(\mathrm{n}=15)$, fluid
(Olive oil brand name: Taris, $\mathrm{n}=15$ ), margarine (brand names: Sana Yag, Yayla Yag, and Evin Yag, $n=15$ ), and mixed types (fluid + cow butter + margarines, $n=15$ ) of oil user. Each groups composed of 18 subjects at the beginning of the experiments. Data about the composition of dietary lipids were given in Table 1 . The predominant polyunsaturated fatty acid (PUFA) in the Turkish diet is linoleic acid (LA; 18:2n-6), an essential fatty acid, which is commonly found in vegetable seed oils. Each diet contains 3 to 9 mg per gram 18:2n-6 fatty acids. Margarines (vegetal) were selected to represents the brands that supply the major part of the margarine eaten in Turkey. The names (Sana Yag, Yayla Yag, Evin Yag, and Taris) are exactly as they appeared on the package labels. The four categories of oil were the only fats in the diets of the participants (except for the usual food fat).

All Subjects have lived in different places during this period. They were advised to eat three similar meals each day with a total daily calorie intake of 1,800-2,000 Kcal (Carbonhydrate 40\%, proteins $20 \%$ ). The amount of oil intake by each participant was total $40 \mathrm{~g}$ fats per day. None of subjects permitted to eat fish and other white meat. All participants were man and ranged in age from 20-40 all years. All subjects were examined before the study and reported to be in good health with no known metabolic disorder and no under medical treatment. 60 subjects received their normal diet during four months. Venous blood samples were taken in heparinized tubes.

Leukocytes isolation was prepared by using a modification of dextran sedimentation method (Bretz et al., 1974; Kelmpner et al., 1978). Briefly, a total of $10 \mathrm{ml}$ of heparin-anticoagulated blood was mixed with $5 \mathrm{ml}$ of a $6 \%$ dextran solution, and the mixture was incubated at room temperature (RT) for $60 \mathrm{~min}$ to allow aggregation and sedimentation of the erythrocytes. The leukocyte-rich supernatant was then mixed with $10 \mathrm{ml}$ of phosphate-buffered saline (PBS) whose $\mathrm{pH}$ is 7.0. Then, the mixture was spun at $160 \times \mathrm{g}$ for $5 \mathrm{~min}$ at

Table 1. The composition of dietary lipids (Butter, margarine, olive oil and mixed oil; Baysal 1992)

\begin{tabular}{|c|c|c|c|c|}
\hline Fatty acids & Butter & Margarine & Olive oil & Mixed oil \\
\hline Saturated & $\% 66$ & $\% 21$ & $\% 14$ & $\% 34$ \\
\hline Butiric (4:0) & + & - & - & + \\
\hline Caprilic (8:0) & + & + & - & + \\
\hline Capric $(10: 0)$ & + & + & + & + \\
\hline Lauric $(12: 0)$ & + & + & + & + \\
\hline Miristic (14:0) & + & + & + & + \\
\hline Palmitic (16:0) & + & + & + & + \\
\hline Stearic $(18: 0)$ & + & + & + & + \\
\hline Arachidic (20:0) & + & + & + & + \\
\hline Lignoceric (24:0) & - & + & - & + \\
\hline Monounsaturated & $\% 30$ & $\% 54$ & $\% 77$ & $\% 54$ \\
\hline Palmitoleic (16:1n-7) & + & + & + & + \\
\hline Oleic $(18: \ln -9)$ & + & + & + & + \\
\hline Elaidic $(18: 1 n-9)$ & + & + & + & + \\
\hline Eicosamonoenic (20:1n-9) & Trace & + & Trace & + \\
\hline Erucic $(22: 1 n-9)$ & Trace & Trace & - & Trace \\
\hline Polyunsaturated & $\% 4$ & $\% 25$ & $\% 9$ & $\% 13$ \\
\hline Linoleic (18:2n-6) & + & + & + & + \\
\hline Linolenic (18:3n-3) & + & + & + & + \\
\hline
\end{tabular}


RT. The cell pellet was suspended in $1 \mathrm{ml}$ of $0.9 \% \mathrm{NaCl}$ for $10 \mathrm{~min}$ to rupture the remaining erythrocytes. The cells were then washed once in PBS and centrifuged at $160 \times g$ for $10 \mathrm{~min}$. The final leukocyte pellet was re-suspended in $2 \mathrm{ml}$ of cold distilled water containing $1.8 \% \mathrm{NaCl}$ (for osmotic shock application) (Bretz et al., 1974; Kelmpner et al., 1978) to remove the remaining erythrocytes. After the suspension was mixed, centrifuged immediately for $5 \mathrm{~min}$, and supernatant was removed. Then, $1 \mathrm{ml}$ distilled water was added into the final leukocyte pellet and samples were placed at $-20^{\circ} \mathrm{C}$ to lyse cells. To this suspension, $0.5 \mathrm{ml}$ Triton-x 100 (\%1) (Bronton, 1966; Mc Nutt, 1977) and $3 \mathrm{ml}$ of $0.9 \% \mathrm{NaCl}$ were added and the suspension was incubated at RT until the separation of membrane was achieved (approximately $15 \mathrm{~min}$ ). The membrane pellet formation was monitored microscopically. The suspension was centrifuged at $3300 \times \mathrm{g}$ for $15 \mathrm{~min}$ at $4^{\circ} \mathrm{C}$ and membrane pellets were stored at $-80^{\circ} \mathrm{C}$ until used.

Extraction of lipids. Total membrane lipids were extracted by a published method (Hebert et al., 1965) from the membrane particles prepared as described above. Phospholipids were purified by thin layer chromatography (TLC) on silica gel-G, chloroform/ methanol/ammonia $(60 / 35 / 5, \mathrm{v} / \mathrm{v})$ eluent. The main advantage of TLC is to separate polar lipids for early separation of phospholipids from neutral lipids for early separation of phospholipids from other lipids (Rouser et al., 1970). $1 \mathrm{ml}$ of tris buffer $(\mathrm{pH}=8)$ was added to that lipid component obtained. To this mixture, $20 \mu \mathrm{l}$ of phospholipase B enzyme, which catalyses the hydrolysis of ester linkages in phospholipids, was added (Kates et al., 1965; Saito et al., 1974).

Hydrolysis was carried out by ultrasonication plus phospholipase B. In order to test whether hydrolysis of phospholipids is achievable or not, $1 \times 5 \mathrm{~cm}$ commercially available TLC plates were utilized. A phospholipid spot seen before hydrolysis was not detected, thus indicating that both of the ester linkages had been hydrolyzed. After that, the samples were mixed with $1 \mathrm{ml}$ of chloroform. The chloroform phase obtained was put into special chromatography tubes. Again $1 \mathrm{ml}$ of chloroform was added and the tube was shaken up and down 2-3 times and dried under nitrogen. Then, $100 \mu \mathrm{l}$ of chloroform was added and covered with a teflon-coated aluminum lid and stored at $-80^{\circ} \mathrm{C}$ in deep freeze until assayed.

\section{Capillary Gas-Liquid Chromatographic conditions for fatty acid} analysis. Analysis were performed by Gas-Liquid Chromatography (Carlo Erba Vega, 6000, Milan, Italy) using a $30 \mathrm{~cm} \times 0.32 \mathrm{~mm}$ i.d. capillary column (CP Wax 52CB, Chromopak, London, UK). Nitrogen was used as carrier gas. Nitrogen gas flow rate was $20 \mathrm{ml} /$ min in the column. Splitless injection was used with the purge off from time 0 to $1.0 \mathrm{~min}$, with $2 \mu \mathrm{l}$ injection volume. Both injection and detector temperatures were $250^{\circ} \mathrm{C}$. The oven temperature was held at $110^{\circ} \mathrm{C}$ for $10 \mathrm{~min}$ and then increased to $180^{\circ} \mathrm{C}$ at a rate of $14^{\circ} \mathrm{C} / \mathrm{min}$. Methylation was done with small modification according the $\mathrm{BF}_{3}$-methanol procedure of Morrision and Smith (Morrison et al., 1964).

Statistical analysis. All values are reported as the mean $\pm \mathrm{SD}$. The number of replicates was twice for each data points. The statistical significance among groups was estimated by one-way ANOVA. Values of $p<0.05$ were considered to be statistically significant.

\section{Results}

Accumulation of oleic acid and stearic acid in the leukocyte membrane could not be observed when the subjects were fed in the presence of solid and fluid oils. Table 2 indicated that leukocyte membrane FAs (both saturated and unsaturated) of the butter-feeding group is given in Fig. 1. In this chromatogram, there were significant peaks in arachidic (20:0), dihomo- $\gamma$ linolenic (20:3n-6), palmitoleic (16:1n-7), linoleic (18:2n-6), palmitic (16:0), caprilic (8:0), capric (10:0) and lauric (12:0) acids, respectively. Fig. 2 shows the chromatogram of the leukocyte membrane FAs of the fluid oil-feeding group; significant peaks in eicosadienoic (20:2n-9), eicosamonoenoic (20:1n-9), dihomo- $\gamma$-linolenic (20:3n-6), behenic (22:0), pelargonic (9:0), linolenic (18:3n-3) and caproic (6:0) acids were detected. In margarine-feeding group, the peaks belonging to heptanoic (7:0), valeric $(5: 0)$, eicosadienoic (20:2n-9), linolenic (18:3n-3) and arachidic (20:0) acids were observed (Fig. 3). On the other hand, the chromatogram of the mixed-oil feeding group revealed the peaks of arachidic (20:0), dihomo- $\gamma$-linolenic (20:3n-6), palmitoleic (16:1n-7), linoleic (18:2n-6), lignoseric (24:0), caprilic (8:0), capric (10:0), lauric (12:0) acids (Fig. 4). The results were evaluated by comparing with the standard chromatogram (Fig. 5).

The statistical differences in the amount of various FAs were given as a mass ratio in Table 2. As seen from the Table 2 , there were statistically significant differences between the groups in terms of FAs contents of leukocyte membrane $(p<$ 0.0001).

\section{Discussion}

In the present study, in the butter-feeding group, it was observed that the amount and number of SFAs were greater than those of unsaturated FAs, and that amount of long chain FAs was much greater than that of small chain FAs and our results were in agreement with Keles et al. (2000), who worked with plasma membranes of neutrophils fatty acid composition. In the fluid oil-feeding group, the amounts of unsaturated FAs and long chain FAs were found to be increased when compared to those of saturated and smallchain FAs, respectively. Our observations are in accordance with the results reported by Pagnan et al (1989), who worked with erythrocytes membrane lipids induced by olive oil-rich diet. Caproic (6.0), pelargonic (9:0) and behenic (22:0) acids, as the SFAs were detected in this group. Controversial results were also obtained in the margarine-feeding group when compared with the other groups.

Up to 6 (or 4) carbon atoms are considered "short-chain organic acids", they are more rapidly digested, generally used energy source, and absorbed in the intestinal tract and have unique properties in regulating sodium and water absorption through the mucosal epithelium (Montgomery et al., 1996). Valeric acid-oxidation products of oils and fats (5:0), heptanoic (7:0) acids were detected in the chromatogram of this group. 
Table 2. Percent of fatty acids, and ratios of mass saturated/ mass unsaturated and long-chain/short-chain fatty acid in leukocyte membrane of the groups

\begin{tabular}{|c|c|c|c|c|c|}
\hline Fatty Acid Name & $\begin{array}{c}\mathrm{n}=15 \\
\text { Butter } \\
(\mathrm{x} \pm \mathrm{SD})\end{array}$ & $\begin{array}{c}\mathrm{n}=15 \\
\text { Margarine } \\
(\mathrm{x} \pm \mathrm{SD})\end{array}$ & $\begin{array}{l}\mathrm{n}=15 \\
\text { Fluid oil } \\
(\mathrm{x} \pm \mathrm{SD})\end{array}$ & $\begin{array}{c}\mathrm{n}=15 \\
\text { Mixed } \\
(\mathrm{x} \pm \mathrm{SD})\end{array}$ & $p<$ \\
\hline Valeric $(5: 0)$ & NA & $24.98 \pm 2.63$ & NA & ND & \\
\hline Caproic (6:0) & NA & NA & $1.74 \pm 0.27$ & ND & \\
\hline Heptanoic (7:0) & NA & $26.90 \pm 2.50$ & NA & ND & \\
\hline Caprilic (8:0) & $2.65 \pm 0.48$ & NA & NA & $4.26 \pm 0.25$ & 0.0001 \\
\hline Pelargonic(9:0) & NA & NA & $6.93 \pm 1.26$ & ND & \\
\hline Capric (10:0) & $1.92 \pm 0.20$ & NA & NA & $3.22 \pm 0.10$ & 0.0001 \\
\hline Lauric (12:0) & $0.03 \pm 0.009$ & NA & NA & $2.91 \pm 0.16$ & 0.0001 \\
\hline Palmitic (16:0) & $3.20 \pm 0.20$ & NA & NA & ND & \\
\hline Palmitoleic (16:1n-7) & $7.45 \pm 0.80$ & NA & NA & $14.58 \pm 0.48$ & 0.0001 \\
\hline Linoleic (18:2n-6) & $6.71 \pm 0.54$ & NA & NA & $9.15 \pm 0.18$ & 0.0001 \\
\hline Linolenic (18:3n-3) & NA & $16.70 \pm 2.13$ & $3.30 \pm 0.74$ & ND & 0.0001 \\
\hline Arachidic $(20: 0)$ & $47.72 \pm 3.31$ & $12.30 \pm 1.87$ & NA & $33.35 \pm 3.28$ & 0.0001 \\
\hline Eicosamonoenoic (20:1n-9) & NA & NA & $18.21 \pm 1.02$ & ND & \\
\hline Eicosadienoic $(20: 2 n-9)$ & NA & $19.12 \pm 2.15$ & $55.01 \pm 2.40$ & ND & 0.0001 \\
\hline Dihomo- $\gamma$-linolenic (20:3n-6) & $30.32 \pm 1.69$ & NA & $7.48 \pm 1.20$ & $28.04 \pm 2.43$ & 0.0001 \\
\hline Behenic $(22: 0)$ & NA & NA & $7.40 \pm 1.35$ & ND & \\
\hline Lignoseric $(24: 0)$ & NA & NA & NA & $4.47 \pm 0.55$ & \\
\hline $\begin{array}{l}\text { Saturated fatty acids/unsaturated } \\
\text { fatty acids }\end{array}$ & 1.24 & 1.79 & 0.19 & 0.93 & \\
\hline $\begin{array}{l}\text { Long-chain fatty acids/short } \\
\text {-chain fatty acids }\end{array}$ & 20.74 & 0.92 & 10.53 & 8.6 & \\
\hline
\end{tabular}

NA: Not avaible

ND: Not detected

$P$ values that were less than 0.001 were considered remarkable.

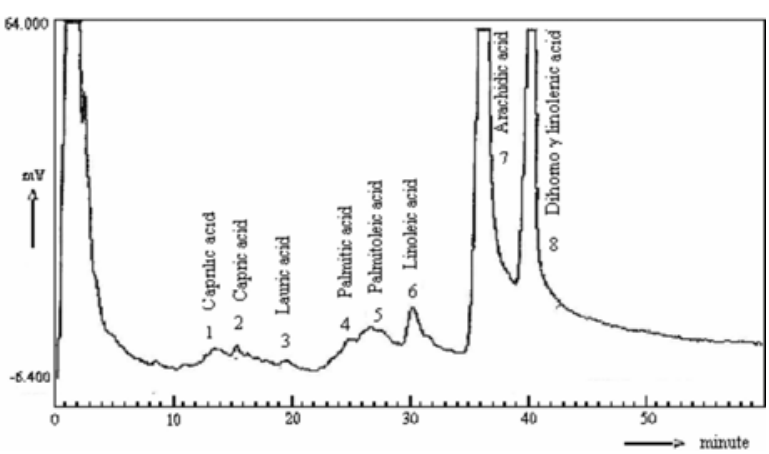

Fig. 1. Typical chromatogram of leukocyte membrane fatty acids in the butter-feeding group.

In the mixed-feeding group, the amounts of saturated and long-chain FAs were greater than those of the unsaturated and short-chain FAs and lignoseric acid (24:0) was detected only in this group. The percent amounts and ratios of saturated/ unsaturated and long-chain/short-chain FAs in the groups were given in Table 2. That the butter-feeding group had high levels of arachidic (20:0) and dihomo-g-linolenic (20:3n-6) acids, also observed in the mixed-feeding group.

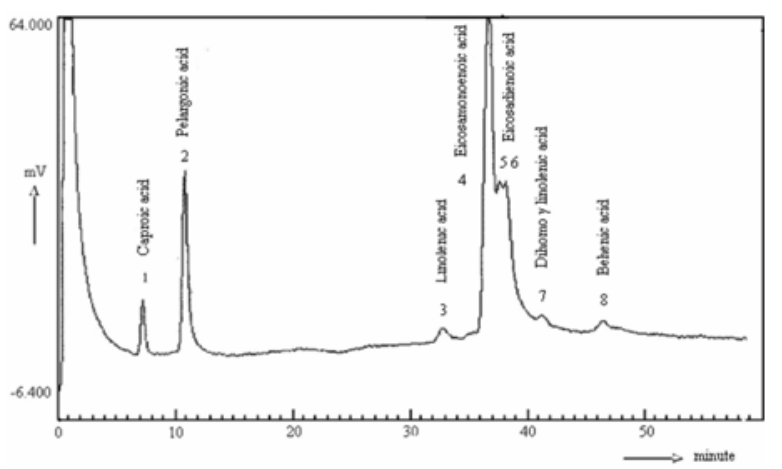

Fig. 2. Typical chromatogram of leukocyte membrane fatty acids in the fluid oil-feeding group.

The FA composition of dietary lipids induces modifications of the cell membranes (Moussa et al., 2000). It is now generally accepted that the levels of blood lipids are influenced by the FA composition of the diet (Mattson et al., 1975). Dietary fat is abnormal determinant of membrane structure, which is a modulator of the biological activity of subcellular membranes and thus of processes that are regulated through membranes (Wicha et al., 1979). 


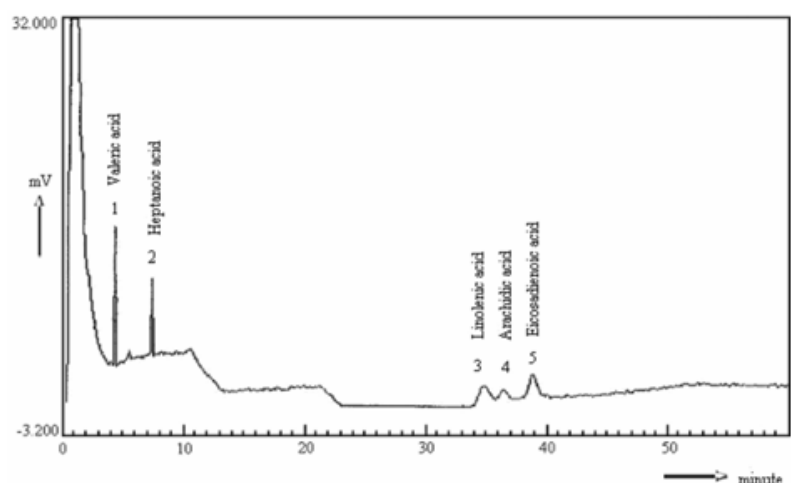

Fig. 3. Typical chromatogram of leukocyte membrane fatty acids in the margarine-feeding group.

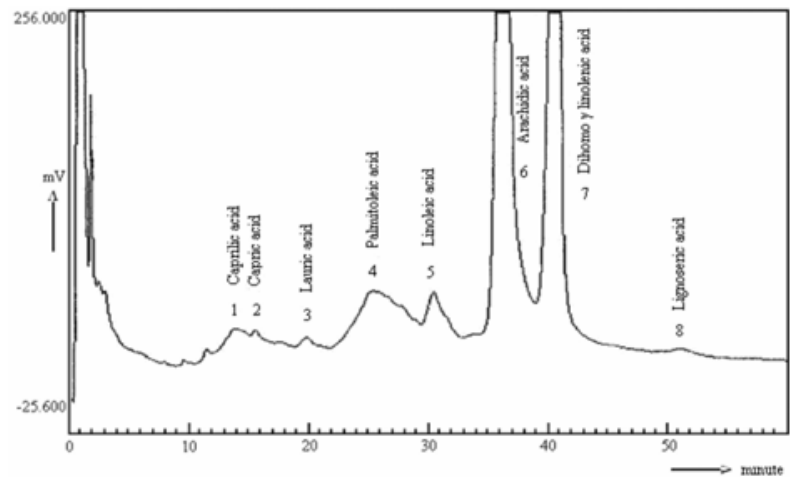

Fig. 4. Typical chromatogram of leukocyte membrane fatty acids in the mixed-oil feeding group.

Increased cellular membrane fluidity is correlated with increased membrane content of PUFAs (Berlin et al., 1980). Changes in membrane fluidity can affect intercellular interaction, receptor expression, nutrient transport and signal transduction (Kelley, 2001). Essential FAs are structural components of cell membranes, required for the growth and maintenance of immune cells, and produced and secreted during immune cell activation. PUFAs with $20 \mathrm{C}$ arachidonic acid, eicosapentaenoic acid and dihomo- $\gamma$-linolenic acid, (20:3n-6) can be metabolized to a variety of eicosanoids, which play important roles in the regulation of immune and inflammatory responses (Kelley, 2001).

One line of evidence suggests that cholesterol and unsaturated FAs exert their effect on immune cells by altering the lipid component of the cell membrane (Frostegard, 2002). When the fluidity of lymphocyte membrane is decreased in the presence of cholesterol, enhanced responses of T-cell to mitogen and increased cytolytic (killer) T-cell activity occur (Heiniger et al., 1978; Kucuk et al., 1994). Membranes having a lower ratio of polyunsaturated to saturated FAs are generally less fluid than those having a higher ratio, which can be affected by the quality of fat fed (Kucuk et al., 1994; Calder, 1995).

In this study, we also reported that leukocyte membrane composition was influenced by solid and fluid oils (Table 2).

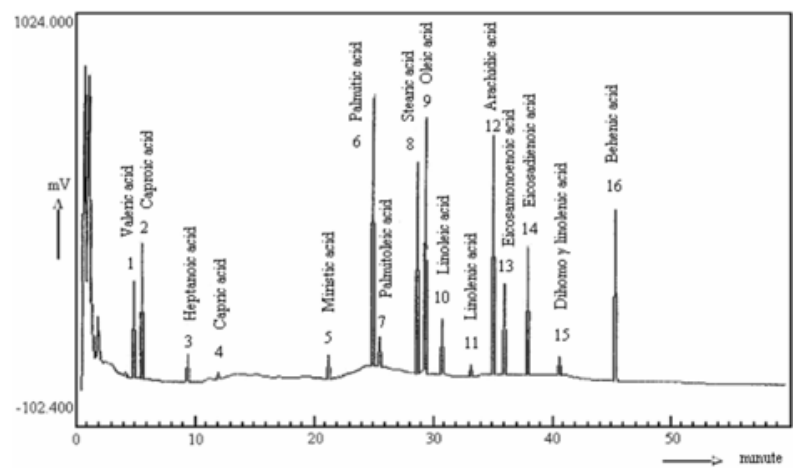

Fig. 5. Chromatogram of fatty acid standards.

Arachidonic (AA) is major components of cell membranes. It is usual to consider that AA is synthesized from their parent precursors, linoleic (LA; 18:2n-6) and $\alpha$-linolenic (ALA; 18:3n-3) acids. However the biosynthetic process is rate limited, especially by the $\Delta^{6}$-desaturase for LA and ALA. An excess of arachidonic acid is harmful (Table 2), and that this is responsible for a range of so-called 'Western' diseases, notably cardiovascular diseases while a deficiency of AA (fluid oil group) in cell membranes classically results in leaking, loss of integrity, and membrane rupture. Arachidonic acid is also the substrate for cytochrome P450-dependent mono-oxygenases, producing molecules regulating ion fluxes in cell membranes (Montgomery et al., 1996; Murray et al., 2000).

In this work, unsaturated $\mathrm{C}-18$ acid present in the nutrition were detected only tiny amounts in the membranes, instead a peak termed as "pelargonic acid" not present in the fat was reported in large amounts (Fig. 2). We have one possible explanation. The linoleic acid in the samples suffered lipid peroxisation and might be cleaved. One of the main cleavage products of linoleic acid is nonadiodic acid, which might have a similar retention time as pelargonic acid.

Also, we reported that some major fatty acids that are almost found are missing, such as those of other C18 fatty acids, even though they are present on dietary lipids are not known. We assumed that the conversion of $\mathrm{C} 18$ fatty acids to observed fatty acids are occurred in leukocyte membranes. Since Oleic (18:1n-9) acid is the precursor of the longer-chain PUFA eicosamonoenoic (20:1n-9), eicosadienoic (20:2n-9) and dihomo- $\gamma$-linolenic (20:3n-6) acids which are important components of membrane phospholipids (Murray et al., 2000), but not may be in leukocyte membranes. Thus conversion of C18 fatty acids by sequential activities of desaturases may be important for maintaining the concentrations of these observed fatty acids in leukocyte membranes. We could not find any similar study, which examined the effect between different type of oil consumption and leukocyte membrane phospholipid composition on human as well as an animal model; thus, we are unable to compare our results with other reports. However, based on our results, it could be said that membrane FAs composition might be affected directly by oil types consumed. 


\section{References}

Barret, K. E. and Metcalfe, D, D. (1984) Mast cell, heterogeneity, evidence and implication. J. Clin. Immunol. 4, 253-261.

Baysal, A. (1992) Diyet yağları ve sağlığımız: Son görüşler. Beslenme ve Diyet Dergisi. 21, 5-16.

Belluzzi, A., Brignola, C., Campieri, M., Pera, A., Boschi, S. and Miglioli, M. (1996) Effect of an enteric-coated fish-oil preparation on relapses in Crohn's disease. N. Engl. J. Med. 334, 1557-1560.

Berlin, E., Matusik, E. J. and Joung, C. (1980) Effect of dietary fat on the fluidity of platelet membranes. Lipids 5, 604-608.

Bretz, U. and Baggiolini, M. (1974) Biochemical and morphological characterization of azurophil and spesific granules of human neutrophilic polymorphonuclear leukocytes. J. Cell. Biol. 63, 251-269.

Bronton, D. (1966) Fracture faces of frozen membranes. Proc. Natl. Acad. Sci. 55, 1048-1056.

Calder, P. C. (1995) Fatty acids, dietary lipids and lymphocyte functions. Biochem. Soc. Trans 23, 302-309.

Calder, P. C. and Zurier, R. B. (2001) Polyunsaturated fatty acids and rheumatoid arthritis. Curr. Opin. Clin. Nutr. Metab. Care. 4, 115-121.

Endres, S., Meydani, S. N., Ghorbani, R., Schindler, R. and Dinarello, C. A. (1993) Dietary supplementation with n-3 fatty acids suppresses interleukin-2 production and mononuclear cell proliferation. J. Leukoc. Biol. 54, 599-603.

Finean, J. B., Colemani, R. and Michell, R. H. (1978) Passage of small molecules; in Membranes and Their Cellular Functions, pp. 42-67, Blackwell Scientific Pub, London. U.K.

Frostegard, J. (2002) Autoimmunity, oxidized LDL and cardiovascular disease. Autoimmun. Rev. 1, 233-237.

Hebert, G. R. and Morris, O. (1965) Improved procedure for the extraction of lipids from human erythrocytes. J. Lipid. Res. 6, 428-431.

Heiniger, H. J., Brunner, K. T. and Cerottini, J. C. (1978) Cholesterol is a critical cellular component for T-lymphocyte cytotoxicity. Proc. Natl. Acad. Sci. USA 75, 5683-5687.

Hopkins, G. J. and West, C. E. (1976) Possible roles of dietary fats in carcinogenesis. Life Sci. 19, 1103-1116.

Kates, M., Modelly, J. R. and Beare, J. L. (1965) Action of phospholipase B on ultrasonically disperdes lecithin. Biochim. Biopyhs. Acta. 106, 630-634.

Keles, M. S., Demir, Y., Altuntas, I., Umudum, Z. and Bakan, E. (2000) Determination of free fatty acid composition in plasma membranes of neutrophils in diabetics. Turk. J. Med. Sci. 30, 465-468.

Kelley, D. S. (2001) Modulation of human immune and inflammatory responses by dietary fatty acids. Nutrition 17, 669-673.

Kelmpner, M. S. and Gallin, J. I. (1978) Separation and functional characterization of human neutrophil subpopulations. Blood 51, 659-669.

Kucuk, O., Stoner-Picking, J., Yachnin, S., Gordon, L. I., Williams, R. M., Lis, L. J. and Westerman, M. P. (1994)
Inhibition of cytolytic $\mathrm{T}$ lymphocyte activity by oxysterols. Lipids 29, 657-660.

Mattson, F. H., Hollenbach, E. J. and Kligman, A. M. (1975) Effect of hydrogenated fat on the plasma cholesterol and triglyceride levels of man. Am. J. Clin. Nutr. 28, 726-731.

Mc Nutt, N. S. (1977) Freeze-fracture techniques and applications to the structural analysis of the mammalian plasma membrane; in Dynamic Aspect of Cell Surface Organisation, Paste, G. and Nicolson, G. L. (eds.), pp. 95-126, Cell Surface Reviews Elsevier, Amsterdam, Netherlands.

Montgomery, R., Conway, T. W., Spector, A. A. and Chappell, D. (1996) Biochemistry, A Case-Oriented Approach, in Lipids Metabolism, Underdown, E. D. (ed.), pp. 295-331, Mosby-Year Book, St. Lous, USA.

Morrison, W. R. and Smith, L. M. (1964) Preparation of fatty acid methyl esters and dimethylacetales from lipids with boron fluoridemethanol. J. Lipid Res. 5, 600.

Moussa, M., Tkaczuk, J., Ragab, J., Garcia, J., Abbal, M., Ohayon, E., Ghisolfi, J. and Thouvenot, J. P. (2000) Relationship between the fatty acid composition of rat lymphocytes and immune functions. Brit. J. Nutr. 83, 327-333.

Murray, R. K., Granner, D. K., Mayes, P. A. and Rodwell, V. W. (2000) Harper's Biochemistry; in Metabolism of Unsaturated Fatty Acids and Eicosanoids, Mayes, P. A. (ed.) pp. 250-258, Appleton \& Lange, New Jersey, USA.

Pagnan, A., Corrocher. R., Ambrosio, G. B., Ferrari, S., Guarini, P., Piccolo, D., Opportuno, A., Bassi, A., Olivieri, O. and Baggio, G. (1989) Effects of an olive-oil-rich diet on erythrocyte membrane lipid composition and cation transport systems. Clin. Sci. (Lond). 76, 87-93.

Rouser, G., Fkeischer, S. and Yamamoto, A. (1970) Two dimensional thin layer chromatographic separation of polar lipids and determination phospholipids by phosphorus analysis of spots. Lipids 5, 494-496.

Saito, K. and Kates, M. (1974) Substrate specifity of a highly purified phospholipase B from Penicilium notatum. Biochem. Bophys. Acta 369, 245-253.

Spector, A. A. and Burns, C. P. (1987) Biological and therapeutic potential of membrane lipid modification in tumors. Cancer Res. 47, 4529-4537.

Tinsley, I. J., Schmitz, J. A. and Pierce, D. A. (1981) Influence of dietary fatty acids on the incidence of mammary tumors in the C3H mouse. Cancer Res. 41, 1460-1465.

Wicha, M. S., Liotta, L. A. and Kidwell, W. R. (1979) Effects of free fatty acids on the growth of normal and neoplastic rat mammary epithelial cells. Cancer Res. 39, 426-433.

Yaqoob, P., Newsholme, E. A. and Calder, P. C. (1995) The effect of fatty acids on leucocyte subsets and proliferation in rat whole blood. Nutr. Res. 15, 279-287.

Zurier, R. B., Rossetti, R. G., Seiler, C. M. and Laposata, M. (1999) Human peripheral blood T lymphocyte proliferation after activation of the $\mathrm{T}$ cell receptor: effects of unsaturated fatty acids. Prostaglandins Leukot. Essent. Fatty Acids. 60, 371-375. 